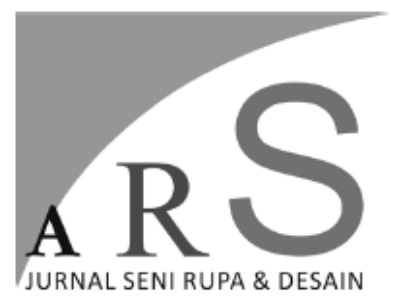

Volume 22 Nomor 3, Desember 2019

\section{KERUSAKAN ALAM SEBAGAI IDE PENCIPTAAN SENI LUKIS}

\author{
Camelia Mitasari Hasibuan \\ Program Studi Seni Rupa Murni, Jurusan Seni Murni \\ Fakultas Seni Rupa Institut Seni Indonesia Yogyakarta \\ E-mail: cameliamitasariH@gmail.com
}

\begin{abstract}
ABSTRAK
Proses pembuatan karya dengan tema dan konsep kerusakan alam ini berdasarkan pengalaman pribadi yang dialami, pengamatan, dan pengumpulan referensi-referensi mengenai kerusakan alam yang terjadi. Melalui karya-karya tersebut, diharapkan pesan mengenai kerusakan alam seperti penebangan illegal hutan, pembunuhan hewan langka, pencemaran lingkungan dan dampak negatif lainnya yang ditimbulkannya dapat tersampaikan kepada apresiator karya. Karya-karya lukisan dua dimensional dalam artikel ini menggambarkan fenomena kerusakan alam yang difantasikan tidak secara nyata namun dilukiskan secara logika (realistik). Aliran Seni yang digunakan untuk melukiskan tema tersebut adalah Surrealisme, sehingga objek sering tampil dengan tidak logis dan imajinatif seakan-akan melukis alam mimpi saja. Aliran Surrealisme figuratif dan Surrealisme murni/photografik dipilih karena aliran ini dapat menampilkan visual fenomena kerusakan alam dalam lukisan dengan bebas berimajinasi dan berfantasi, sehingga dapat lebih menggugah perasaan mengenai suasana kejadian dan dampak yang ditimbulkan dari fenomena kerusakan alam. Objek-objek yang dilukiskan dalam karya-karya dipilih dan dideformasi sesuai dengan fenomena kerusakan alam dan kaitannya dengan subject matter yang diangkat sehingga dapat menggambarkan fenomena kerusakan alam dan dampak yang ditimbulkan.
\end{abstract}

Kata kunci : kerusakan alam, lukisan, surealisme, deformasi, flora fauna.

\begin{abstract}
The process of this artistry making is started with personal experience, observation, and literature review on the destruction of nature. Those artworks deliver message about the negative effects of those damages such as illegal logging, the slaughter of endangered animals, environmental pollution to the audiences. The two dimensional paintings depicts imaginative natural damage phenomena however logically narrated. This natural damage theme is manifested through surrealism style so that the objects are often represented illogically and imaginatively as if what are painted are the dreamland. The Figurative and pure/photographical surrealism are chosen because it is more likely to provoke people to think. about the paintings. The objects painted are selected and deformed to fit the subject matter and its relation to the effects caused.
\end{abstract}

Keywords: natural damage, painting, surrealism, deformation, flora and fauna 


\section{Pendahuluan}

Perkembangan zaman yang semakin canggih membuat alam berubah menjadi tempat yang semakin lama semakin rusak karena kerakusan dan tingkah laku manusia. Selain itu bertambahnya manusia membuat bertambah pula kebutuhan manusia itu sendiri. Kerusakan alam adalah fenomena yang terjadi dimana-mana dan telah terjadi hampir di seluruh penjuru dunia. Fenomena ini terjadi disebabkan oleh alam itu sendiri dan oleh ulah manusia yang tidak bertanggung jawab. Alam sebagai sebuah ekosistem kehidupan di bumi ini memiliki peranan yang sangat penting bagi semua makhluk hidup sebagai penghuninya. "Suatu ekosistem adalah suatu sistem yang berinteraksi terdiri dari sekelompok organisme dengan lingkungan fisiknya" (Sastrawijaya 2009:68) Maka dari itu jika alam dan makhluk hidup di dalamnya memiliki keseimbangan dan dapat berperan dengan baik, alam ini dapat menjadi tempat yang nyaman bagi semua makhluk hidup.

Pembangunan pabrik, pembakaran hutan, sampah dan lain sebagainya menimbulkan kerugian-kerugian seperti polusi, limbah, generasi flora dan fauna yang cacat dan masih banyak lagi. Akibat- akibat dari pengrusakan alam oleh ulah manusia ini pula banyak jenis flora dan fauna mengalami kepunahan. Perbuatan merusak alam yang dilakukan manusia juga berdampak pada kelangsungan hidup dan ekosistem dari makhluk hidup lain, seperti flora (tumbuhan) dan fauna (hewan). Meskipun terkadang alasan kebutuhan dari manusia ini tidak mendasar dan tidak masuk akal. Ada yang berdasarkan mitos maupun hanya untuk dijadikan sebagai bendabenda pelengkap kemewahan.

Beberapa fenomena kerusakan alam terjadi di sekitar lingkungan kita. Salah satunya adalah sungai yang tercemar limbah sampah. Sungai yang semula jernih dan dihuni oleh banyak ikan yang berenang mengikuti aliran arus sungai, kini telah tercemar oleh sampah yang menumpuk. Sampah tersebut dibuang oleh banyak penduduk sekitar ke aliran sungai. Terdiri dari sampah rumah tangga, sampah plastik, dan sebagainya.

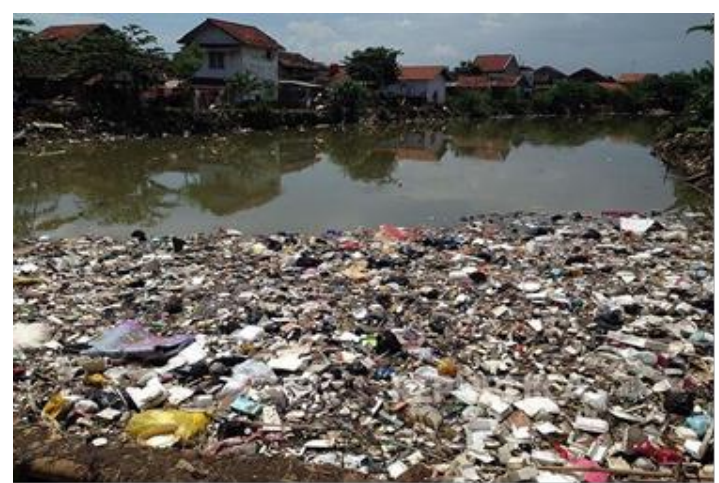

Gambar 1. Sampah-sampah yang menumpuk dan mencemari sungai. (Sumber:

http://nasional.republika.co.id/berita/nasional/da erah/16/03/29/o4syb7280-ridwan-kamilperintahkan-fokus-pengelolaan-sampah-dialiran-sungai :diakses pada Selasa, 28 November 2017 pukul 06.42 WIB )

Masalah sampah yang muncul tersebut salah satunya disebabkan oleh banyaknya bangunan yang berdiri karena bertambahnya jumlah penduduk di desa tersebut. Semula banyak sawah dan pepohonan besar yang ada di lingkungan sekitar tempat tinggal kita. Namun saat ini sawah dan pepohonan tersebut tergantikan dengan bangunan-bangunan perumahan.

Selain berbagai kejadian kerusakan alam yang terjadi di sekitar, banyak peristiwa mengenai kerusakan alam di tempat lain yang terekspose oleh berbagai media massa maupun elektronik. Salah satu contohnya adalah peristiwa pembantaian hewan secara besar besaran dengan sebab yang tidak penting. Seperti pembantaian badak, gajah, buaya, hiu, penyu dan masih banyak lagi. Perburuanperburuan hewan yang dilindungi marak terjadi di berbagai daerah dan dengan bangganya para pemburu illegal ini memamerkan foto-foto perburuan mereka di sosial media. Ada pula masalah limbah dari pabrik-pabrik yang berdiri beserta polusi udara, penambangan yang terus menerus tanpa memikirkan dampak terhadap kelangsungan hidup alam dan isinya dari proses tersebut. Masih banyak lagi peristiwa-peristiwa kerusakan alam yang terjadi sampai saat ini. 


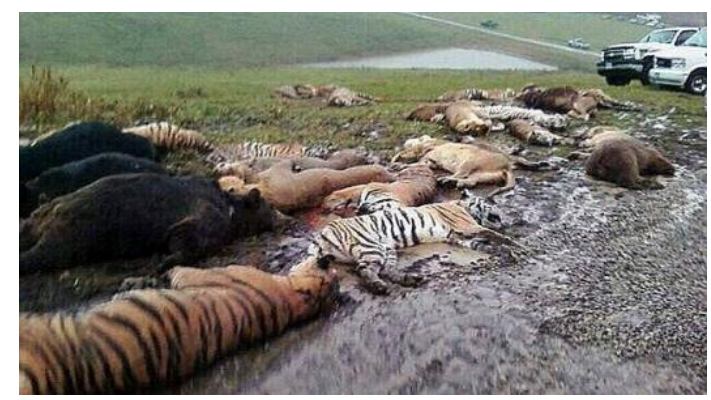

Gambar 2. Pembunuhan hewan-hewan secara besar-besaran.

(Sumber:

https://www.wowkeren.com/berita/tampil/000122

76.html : diakses pada Selasa, 28 Nopember 2017 pukul 06.50 WIB )

Berdasarkan latar belakang di atas, untuk mewujudkan realita kerusakan alam akibat keserakahan manusia yang berdampak pada flora dan fauna dalam karya seni lukis, ada beberapa pertanyaan mendasar yakni kerusakan alam apa saja yang akan dieksplorasi, deformasi bentuk objek seperti apa saja yang tepat divisualkan hingga persoalan teknik maupun medium apakah yang digunakan dalam memvisualisasikan kerusakan alam tersebut dalam media dua dimensional? Dengan demikian karya seni lukis ini masyarakat lebih menyadari fenomena kerusakan alam dan pentingnya ekosistem untuk dapat menjaga alam ini serta menuangkan ekspresi melalui tema kerusakan alam dengan deformasi yang tepat melalui berbagai teknik dan medium cat minyak ke dalam bidang dua dimensional kanvas. Dari peristiwa-peristiwa dan pengalamanpengalaman di atas, maka lahirlah judul artikel penciptaan karya yaitu Kerusakan Alam Sebagai Ide Penciptaan Seni Lukis.

\section{Pembahasan}

1. Konsep Penciptaan

Lukisan adalah hasil karya seni yang merupakan cerminan dari jiwa pribadi seorang pelukis yang divisualisasikan ke dalam bidang dua dimensional. Seniman yang melihat dan kemudian perasaannya tergugah saat melihat dan mengetahui sebuah peristiwa penderitaan, keserakahan, kerusakan alam yang tidak bertanggungjawab terhadap flora dan fauna yang tidak bersalah dan tidak dapat berbuat apa-apa.
Banyak pelukis-pelukis yang mengangkat tema tentang alam dan keindahannya. Alam dapat menjadi sumber konsep, ide, maupun bahan dalam karya seni khususnya karya dua dimensional. Beberapa diantaranya adalah Nasirun, Wayan Cahya, Husin Hasibuan, Dulk, Craola, Jacub Gagnon, Martin Wittfooth dan lain sebagainya. Proses pembuatan karya dengan tema dan konsep kerusakan alam ini berdasarkan pengalaman pribadi yang dialami, pengamatan, dan pengumpulan referensi-referensi mengenai kerusakan alam yang terjadi. Melalui karyakarya tersebut, diharapkan pesan mengenai kerusakan alam yang terjadi dan dampak negatif yang ditimbulkan dapat tersampaikan publik yang menikmatinya.

Tema kerusakan alam dan kejadiankejadian yang ada didalamnya dituangkan dalam karya seni lukis dengan aliran surrealisme. "Surrealisme ini sendiri berasal dari bahasa Perancis, Sur $=$ di atas, realism $=$ hal-hal yang bersifat nyata/kenyataan". (Sugianto 2002:87) Surrealisme yang dipilih adalah surrealism murni/photografik, karena objek dapat dilukiskan secara realistik serta dapat lebih mudah dalam proses dramatis pada karya dan lebih mudah dalam penyampaian pesan dalam karya kepada publik yang melihatnya. Lebih lanjut menurut Wardoyo (2002:88) dalam perkembangannya kemudian Surrealisme menghasilkan dua tendensi (kecenderungan) yaitu :

a. Surrealisme Ekspresif

Dimana si seniman melewati semacam kondisi tidak sadar, kemudian melahirkan simbol-simbol dan bentukbentuk dari perbendaharaannya yang terdahulu. Yang tergolong dalam tendensi ini ialah : Andre Masson, Joan Miro dan Marc Chagall.

b. Surrealisme Murni/Photografik

Dalam hal ini seniman menggunakan teknik-teknik akademik untuk menciptakan ilusi yang absurd. Tokoh utamanya adalah: Salvador Dali.

Karya-karya lukisan yang akan ditampilkan menggambarkan fenomena 
kerusakan alam yang difantasikan tidak secara nyata dilukiskan secara logika. Seni Surrealisme sering tampil dengan tidak logis dan penuh fantasi, seakan-akan melukis alam mimpi saja. Segala ketidakmungkinan dapat muncul dalam lukisan Surrealis. (Rasjoyo, 1994:55) Suasana dan objek yang dilukiskan dalam karya-karya beraliran surrealis figuratif dan tidak diabstraksikan.

a. Surrealis Figuratif

Surrealis jenis ini masih menampilkan bentuk nyata dan wajar, yang disusun dalam struktur yang fantastis. Sehingga pelukis aliran ini harus menguasai teknik dan bahan secara baik. Tokoh aliran Surrealis jenis ini adalah Salvador Dali, Max Ernest, Odilon Redon dan Marc Chagall.

b. Surrealis Abstraktif

Surrealisme jenis ini tidak lagi menggunakan ingatan sebagai sumber atau tempat objek. Objek-objek yang muncul sering berupa simbol-simbol bawah sadar. Tokoh-tokoh aliran ini adalah Andre Masson dan Joan Miro. Aliran Surrealisme figuratif dan Surrealisme murni/photografik dipilih karena aliran ini dapat menampilkan visual fenomena kerusakan alam dalam lukisan dengan bebas berimajinasi dan berfantasi, sehingga dapat lebih menggugah perasaan mengenai suasana kejadian dan dampak yang ditimbulkan dari fenomena kerusakan alam. Objekobjek yang dilukiskan dalam karya-karya dipilih dan dideformasi sesuai dengan fenomena kerusakan alam dan kaitannya dengan objek-objek tersebut sehingga dapat menggambarkan fenomena kerusakan alam dan dampak yang ditimbulkan dari fenomena tersebut. Namun tidak semua objek dideformasi. Objek-objek yang dideformasi disesuaikan dengan konsep dan ide yang dipilih dalam setiap karya lukisan yang dibuat. Mikke Susanto (2011, 98) menyatakan deformasi adalah perubahan susunan bentuk yang dilakukan dengan sengaja untuk kepentingan seni, yang sering terkesan sangat kuat/besar sehingga kadang- kadang tidak lagi berwujud figur semula atau sebenarnya. Sehingga hal ini dapat memunculkan figur/karakter baru yang lain dari sebelumnya."

2. Teknik Penciptaan Lukisan

Aliran Surrealisme figuratif dan Surrealisme Murni/Photografik dipilih karena aliran ini dapat menampilkan visual fenomena kerusakan alam dalam lukisan dengan bebas berimajinasi dan berfantasi. Lukisan dengan aliran ini, objek-objek yang ditampilkan dalam bentuk yang figuratif atau masih terlihat bentuk dan figur dari objek tersebut. Objek-objek dalam karya dibuat dengan teknik Realis. Teknik ini digunakan untuk membuat objek semirip mungkin dengan objek asli tanpa menghilangkan maupun menambahkan ciri dari bentuk objek tersebut.

Objek-objek tersebut kemudian dideformasi dan digabungkan dengan objek-objek alam lainnya sesuai imajinasi mengenai fenomena kerusakan alam yang diangkat dalam karya. Deformasi dan penggabungan beberapa objek dilakukan untuk dapat mendramatisir suasana fenomena kerusakan alam dalam karya. Sehingga dapat tercipta suasana aliran Surrealisme dalam karya.

Teknik opaque dengan menggunakan cat minyak dipakai untuk mendapatkan warna sesuai dengan yang diimajinasikan. "Cat minyak mempunyai sifat opaque (menutup), artinya satu warna dapat menutup warna lain dibawahnya." Teknik pengecatan yang berulang-ulang hingga beberapa lapis sampai warna dan detail karya dapat tercapai. Sifat cat minyak yang dapat menutup warna sebelumnya dapat memudahkan dalam membuat detail dan objek secara realis, sehingga bentuk-bentuk dan suasana imajinasi mengenai fenomena kerusakan alam dalam karya dapat dicapai sesuai yang diinginkan.

3. Deskripsi Karya

Lukisan adalah salah satu hasil dari berbagai ide dan gagasan yang dituangkan dengan berbagai bentuk ke dalam bidang dua dimensional, sehingga dapat dilihat dan dirasakan oleh pembuat maupun oleh publik maupun penikmat seni. Pada setiap 
karya lukisan yang dibuat memiliki salah satu fungsi penting yaitu makna yang terkandung di dalamnya.

Makna yang terkandung dalam lukisan dapat memberikan persepsi atau cara pandang yang berbeda pada setiap penikmat yang memandangnya, sehingga dapat menimbulkan berbagai tanggapan dalam bentuk apresiasi pada karya lukisan tersebut. Perbedaan pendapat dan cara pandang pada setiap orang dalam memandang karya lukisan pasti akan terjadi, sehingga diperlukan sebuah ulasan terhadap suatu karya yang fungsinya menjadi sebagai sebuah jembatan komunikasi antara pelukis dengan penikmatnya.

Secara keseluruhan karya tugas akhir ini menghadirkan 20 karya lukisan yang bertajuk "Kerusakan Alam Sebagai Ide Penciptaan Seni Lukis". Dalam tinjauan karya ini, dijelaskan makna dari setiap karya serta bagaimana kaitannya dengan konsep yang diangkat.

Alam memberikan banyak manfaat bagi semua makhluk hidup di bumi ini. Sebagai rumah, tempat berkembang biak, tempat berlindung, lahan mencari makan dan lain sebagainya. Namun seiring dengan kemajuan zaman, alam yang awalnya sejuk, indah, hijau telah berganti menjadi semakin rusak. Alam beralih fungsi menjadi tempat bagi sampah sisa perkembangan zaman yang semakin maju ini. Bagi makhluk hidup lain selain manusia, yakni flora dan fauna. Kejadian ini menjadi sebuah bencana bagi mereka. Habitat nyaman dengan banyak pohon hijau dan udara yang sejuk telah berganti menjadi tanah gersang, lempenganlempengan besi berkarat dan udara yang terpolusi akibat dari sampah-sampah sisa hasil dari perkembangan teknologi. Burung, sebagai salah satu fauna yang sangat bergantung pada pohon dan alam harus dapat beradaptasi di lingkungan barunya yang buruk tersebut, atau mereka akan punah.

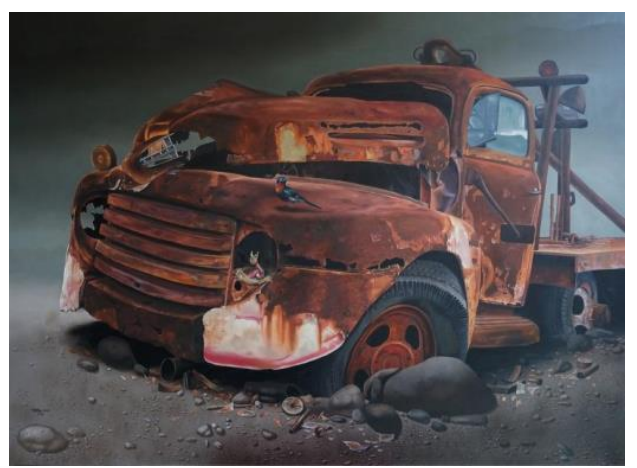

Gambar 3. Adaptasi, Oil On Canvas, $100 \mathrm{~cm} \mathrm{X} 135 \mathrm{~cm}, 2015$.

(Sumber: Dokumentasi Camelia Mitasari Hasibuan)

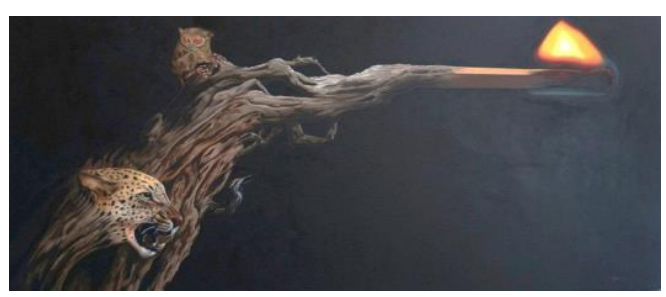

Gambar 4. Gara-gara Setitik Api, Oil On Canvas, 75 cm X 175 cm, 2016.

(Sumber: Dokumentasi Camelia Mitasari Hasibuan)

Pohon adalah salah satu tempat bagi beberapa jenis hewan. Pohon menyumbang begitu banyak hal kepada alam, hewan maupun manusia. Manusia pasti membutuhkan kayu, dan kayu berasal dari pohon. Salah satu ciptaan manusia dari bahan baku kayu adalah korek api. Batang korek api yang terbuat dari kayu pohon justru sering digunakan untuk membakar pepohonan di hutan. Sehingga banyak binatang yang membutuhkan pohon menjadi tersingkirkan.

Beragam penghuni alam ini dan bagian-bagian alam yang saling melengkapi satu sama lain, bahkan unsur-unsur alam turut pula menyumbang dalam proses kehidupan makhluk hidup lainnya. Namun, akibat dari fenomena kerusakan alam hidup dari flora, fauna maupun unsur-unsur alam lain hanya tinggal menunggu kepunahan dan hanya akan terpajang dalam bingkai kehidupan nantinya sebagai sebuah kenang-kanangan abadi dalam memori. 

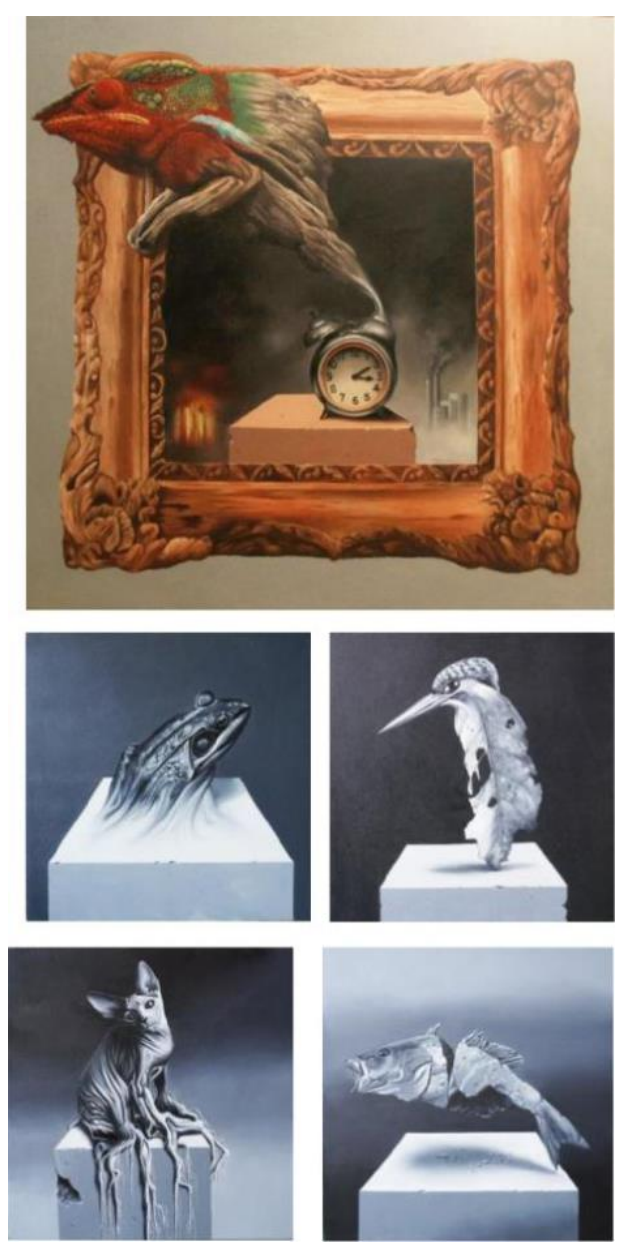

Gambar 5. Menunggu Waktu, Oil On Canvas,

$100 \mathrm{~cm} \times 100 \mathrm{~cm}$ ( 1 panel )

dan $40 \mathrm{~cm} \mathrm{X} \mathrm{40cm} \mathrm{(} 4$ panel ), 2015 .

(Sumber: Dokumentasi Camelia Mitasari Hasibuan

\section{Kesimpulan}

Berawal dari ide atau gagasan yang kemudian divisualkan dalam bentuk karya seni, sehingga banyak catatan yang dapat menjadi pelajaran penting dan berharga dalam proses berkarya maupun pengetahuan lebih mengenai alam dan isinya. Beberapa faktor-faktor penyebab terjadinya kerusakan alam oleh ulah manusia dan dampak negatif yang dialami oleh makhluk hidup lain seperti tumbuhan dan hewan dieksplorasi dan digambarkan dalam bidang dua dimensi dengan aliran surrealisme. Objek-objek dideformasi dengan bentukbentuk unsur alam untuk dapat mendramatisir penggambaran suasana kerusakan alam dalam karya seni lukis. Hal tersebut bertujuan agar pesan yang terkandung mengenai kerusakan alam yang terjadi dalam karya-karya yang dibuat dapat tersampaikan dengan baik kepada publik yang melihatnya.

Alam memberikan banyak pelajaran, seperti bagaimana harus bersikap dan berinteraksi dengan yang lain, saling menghormati, menjaga, melestarikan, dan menyayangi antar makhluk, seperti dalam karya berjudul "Menunggu Waktu". Karya tersebut menggambarkan keterkaitan antar makhluk hidup dengan alam serta akibat dari fenomena kerusakan alam. Karena bahkan dalam segenggam tanah pun terdapat begitu banyak makhluk hidup di dalamnya.

Alam, manusia serta seluruh unsurunsur alam yang terdapat di dalamnya tidak dapat dipisahkan, sehingga kita sebagai manusia yang diberikan kelebihan akal pikiran harus dapat lebih melestarikan alam, saling menghargai dan menjaga antar sesama ciptaan Tuhan. Kerusakan alam yang terjadi di berbagai tempat di bumi ini menjadi sebuah pelajaran penting dan dapat lebih menyadarkan penulis bahwa hal kecil yang kita lakukan dapat berdampak besar terhadap alam. Besar harapan melalui penciptaan lukisan ini semoga dapat memberikan kontribusi dalam perkembangan seni lukis maupun dalam usaha menyadarkan masyarakat mengenai pentingnya merawat alam ini. 


\section{Daftar Pustaka}

Rasjoyo. 1994. Pendidikan Seni Rupa. Jakarta: Erlangga.

Sastrawijaya, A. Tresna. 2009. Pencemaran Lingkungan. Jakarta: Rieneka Cipta.

Sugianto, Wardoyo. 2002. Sejarab Seni Rupa Barat. Yogyakarta: ISI Yogyakarta.

Susanto, Mikke. 2011. Diksi Rupa. Yogyakarta: DiktiArt Lab \& Djagad Art House.

\section{Webtografi}

http://nasional.republika.co.id

https://www.wowkeren.com 